\title{
……
}

RESEARCH AND EDUCATION

\section{Effect of photodynamic therapy on the mechanical properties and bond strength of glass-fiber posts to endodontically treated intraradicular dentin}

\author{
Henrico Badaoui Strazzi Sahyon, DDS, MS, ${ }^{a}$ Paloma Pereira da Silva, DDS, ${ }^{\mathrm{b}}$ Murilo Silva de Oliveira, DDS, ${ }^{\mathrm{c}}$ \\ Luciano Tavares Angelo Cintra, DDS, MS, PhD, ${ }^{d}$ João Eduardo Gomes-Filho, DDS, MS, PhD, \\ Paulo Henrique dos Santos, DDS, MS, PhD, and Gustavo Sivieri-Araujo, DDS, PhD $^{\mathrm{f}}$
}

Endodontically treated teeth with excessive loss of coronal structure are commonly restored with glass-fiber posts. ${ }^{1-3}$ Disinfection of the root canal systems and a long-lasting restoration are essential goals for successful treatment. Microbial reduction is typically achieved with biomechanical instrumentation of the root canal, ${ }^{4}$ sodium hypochlorite irrigating solution, ${ }^{5-7}$ and calcium hydroxide intracanal medication. ${ }^{8,9}$ However, these procedures cannot ensure the total eradication of bacteria and their toxic products from the root canal. ${ }^{10-12}$ Consequently, therapeutic approaches, including photodynamic therapy (PDT), have been introduced to reduce endodontic infections.

PDT involves the absorption of photons by photosensitizers

\begin{abstract}
Statement of problem. The use of photosensitizers in photodynamic therapy promotes intraradicular microbial reduction during nonsurgical endodontic therapy. However, studies are lacking on the consequences of the application of these agents on the mechanical properties of intraradicular dentin and on the bond strength of glass-fiber posts.
\end{abstract}

Purpose. The purpose of this in vitro study was to evaluate the influence of photodynamic therapy on the bond strength of glass-fiber posts using a push-out test and, additionally, to measure the Martens hardness $(\mathrm{MH})$ and elastic indentation modulus (Eit) of intraradicular dentin when different photosensitizers are used.

Material and methods. Eighty bovine teeth were used to simulate experimental endodontic treatments. Biomechanical instrumentation was performed for all root canals, and the teeth were distributed into 5 groups: control-deionized water; methylene blue $50 \mathrm{mg} / \mathrm{L}+$ red laser; methylene blue $100 \mathrm{mg} / \mathrm{L}$ + red laser; curcumin $500 \mathrm{mg} / \mathrm{L}$ + blue LED; and curcumin $1000 \mathrm{mg} / \mathrm{L}$ + blue LED. The $\mathrm{MH}$ and Eit of intraradicular dentin were measured using an ultramicrohardness tester under a load of $3 \mathrm{mN}(n=8)$. The push-out bond strength of glass-fiber posts to dentin was measured using a universal testing machine $(n=8)$. Mechanical properties and bond strength data were subjected to the Kruskal-Wallis test, ANOVA, and Fisher least significant difference test $(\alpha=.05)$. Images of representative specimens were obtained using a scanning electron microscope.

Results. The $\mathrm{MH}$, Eit, and bond strength of intraradicular dentin were influenced by the photosensitizer used. In general, curcumin promoted lower mechanical properties values but higher bond strength values.

Conclusions. Photosensitizers influenced the mechanical properties of intraradicular dentin and the bond strength of glass-fiber posts, and methylene blue at $50 \mathrm{mg} / \mathrm{L}$ had no marked effect on the mechanical properties of the dentin or the bond strength values. (J Prosthet Dent 2018;120:317.e1-e7)

\footnotetext{
Funding: This work was supported by São Paulo Research Foundation (FAPESP) (grant: 2015/06056-3) and PROPe-São Paulo State University (grant: 12/2015), Brazil. ${ }^{a}$ Postgraduate student, Department of Dental Materials and Prosthodontics, Araçatuba School of Dentistry, São Paulo State University (UNESP), Araçatuba, Brazil. bDentistry graduate, Department of Restorative Dentistry, Araçatuba School of Dentistry, São Paulo State University (UNESP), Araçatuba, Brazil. ${ }^{c}$ Dentistry graduate, Department of Restorative Dentistry, Araçatuba School of Dentistry, São Paulo State University (UNESP), Araçatuba, Brazil. ${ }^{d}$ Associate Professor, Department of Restorative Dentistry, Araçatuba School of Dentistry, São Paulo State University (UNESP), Araçatuba, Brazil. 'Titular Professor, Department of Restorative Dentistry, Araçatuba School of Dentistry, São Paulo State University (UNESP), Araçatuba, Brazil. ${ }^{\mathrm{f}}$ Associate Professor, Department of Dental Materials and Prosthodontics, Araçatuba School of Dentistry, São Paulo State University (UNESP), Araçatuba, Brazil. ${ }^{\mathrm{g}}$ Assistant Professor, Department of Restorative Dentistry, Araçatuba School of Dentistry, São Paulo State University (UNESP), Araçatuba, Brazil.
} 


\section{Clinical Implications}

The photodynamic therapy associated with methylene blue is a viable clinical procedure for the disinfection of root canals before the luting of glass-fiber posts to intraradicular dentin.

(PSs) from a light source, ${ }^{13}$ allowing the stimulation of electrons from the normal state to an excited phase. In the presence of oxygen, the PSs transfer this energy to the substrate. The return to its ground state promotes formation of highly reactive and short-lived species, related to singlet oxygen, affecting only the target cells and microorganisms through irreversible oxidation. ${ }^{14-16}$

However, the effects of PDT on the mechanical properties of dentin and its possible effect on adhesive restorative procedures are unclear. Therefore, the purpose of this in vitro study was to evaluate the mechanical properties (Martens hardness $[\mathrm{MH}]$ and elastic indentation modulus [Eit]) of intraradicular dentin as well as to determine the push-out bond strength of glass-fiber posts to dentin after PDT with curcumin and methylene blue PSs. The null hypothesis was that different PSs would not cause changes in the mechanical properties of dentin and the bond strength of glass-fiber posts to endodontically treated intraradicular dentin.

\section{MATERIAL AND METHODS}

The materials used in this project are listed in Table 1. The study was approved by the ethics committee of the Araçatuba School of Dentistry, São Paulo State University (15-00688). Eighty bovine teeth were used in this study. Teeth that exhibited cracks or fractures were excluded. A low-speed diamond saw (IsoMet 5000; Buehler) was used to remove the anatomic crowns $1.0 \mathrm{~mm}$ coronal to the cementum-enamel junction. The working length was established to be $1.0 \mathrm{~mm}$ less than this length. The specimens were then endodontically treated. The root canals were instrumented using K-Files \#80 (Dentsply Sirona), irrigated with $1 \%$ sodium hypochlorite, and subsequently dried with a jet of air and sterile paper points. The apical foramen was sealed to prevent escape of the PS. The apices were conditioned with $37 \%$ phosphoric acid (FGM) for 15 seconds, washed, and dried with a jet of air and sterile paper points. Two layers of adhesive (Adper Single Bond 2; 3M ESPE) were applied for 15 seconds to the etched surface, and the material was then polymerized for 20 seconds with a light-polymerization unit (Ultraled; Dabi Atlante). Finally, the apical foramen was sealed with composite resin (Filtek Z250 XT; 3M ESPE) using a Thompson spatula, followed by photoactivation for 40 seconds. The specimens were distributed into 5 experimental groups $(\mathrm{n}=16)$.
In the control group, the root canal was filled with deionized water and did not receive any type of PS or PDT. In the $\mathrm{MB}_{50}$ and $\mathrm{MB}_{100}$ groups, the root canals were filled with methylene blue $(50 \mathrm{mg} / \mathrm{L}$ and $100 \mathrm{mg} / \mathrm{L})$ for 3 minutes (period of preirradiation). ${ }^{17}$ In the $C_{500}$ and $C_{1000}$ groups, the root canals were filled with curcumin $(500$ $\mathrm{mg} / \mathrm{L}$ and $1000 \mathrm{mg} / \mathrm{L}$ ) for 5 minutes. ${ }^{17}$ In all 4 groups $\left(\mathrm{MB}_{50}, \mathrm{MB}_{100}, \mathrm{C}_{500}\right.$, and $\left.\mathrm{C}_{1000}\right)$, the respective PS was carefully shaken for 1 minute in an ultrasonic unit (Nac Plus; Adiel), avoiding contact of the tip with the wall of the root canal.

In the $\mathrm{MB}_{50}$ and $\mathrm{MB}_{100}$ groups, the PS was activated by red laser (Laser Duo; MMO) of $\lambda 660 \mathrm{~nm}$ for 1 minute with a flexible fiber optic of $300-\mu \mathrm{m}$ diameter, $2 \mathrm{~mm}$ apical to the working length. ${ }^{17}$ In the $\mathrm{C}_{500}$ and $\mathrm{C}_{1000}$ groups, the PS was activated by blue LED of $\lambda 480 \mathrm{~nm}$ for 4 minutes. Helicoidal movements were performed in the apicocervical direction with the optical fiber to ensure uniform diffusion of light throughout the root canal. ${ }^{18,19}$ The movements were repeated approximately 10 times $/ \mathrm{min} .{ }^{20}$

The choice of light wavelength is directly related to the absorption characteristics of the PS used. The times of application of each light source (1 minute for laser and 4 minutes for blue LED) were chosen as the amount of time that demonstrated satisfactory antimicrobial activity according to the literature. ${ }^{13,19}$ In addition, MB and curcumin PSs present absorption peaks at 630 to $750 \mathrm{~nm}$ and 450 to $495 \mathrm{~nm}$, with a final energy of $72 \mathrm{~J} / \mathrm{cm}^{2} .{ }^{13,14,19}$

Immediately after the PDT had been performed, the root canals were irrigated with $10-\mathrm{mL}$ deionized water to remove the PS and were subsequently dried with a jet of air and sterile paper points. All the teeth were stored at $100 \%$ relative humidity and $37^{\circ} \mathrm{C}$ for 7 days. ${ }^{21,22}$

Cuts were made perpendicular to the long axis of the specimens ( $\mathrm{n}=8$ per group) using a low-speed diamond saw (IsoMet 5000; Buehler) under water cooling. Approximately $1.3-\mathrm{mm}$-thick slices from each of the three regions (cervical, middle, and apical) were fixed in acrylic resin (Classico). Slices were manually finalized using \#320, \#600, \#800, and \#1200 grit silicon carbide paper (Extec Corp) and polished using diamond pastes $(6,3$, and $1 \mu \mathrm{m}$; Buehler) for 4 minutes per phase. All the specimens were cleaned for 2 minutes in an ultrasonic unit (model 2210; Branson Ultrasonic Corp) containing deionized water between each silicon carbide paper and diamond paste polishing step and at the end of the process. ${ }^{23,24}$

An ultramicrohardness tester (DUH-211; Shimadzu) was used to verify the $\mathrm{MH}$ and Eit under a load of $3 \mathrm{mN}$ at a speed of $0.2926 \mathrm{mN} / \mathrm{s}$ with a holding time of 5 seconds. A Vickers diamond tip was used, and 5 indentations were made on the dentin. ${ }^{23-25}$ The $\mathrm{MH}$ and Eit values were calculated automatically by the software in the hardness tester, and the arithmetic mean between the different thirds was calculated for each specimen. The 
Table 1. Materials, classification, composition, batch number of materials, and manufacturer

\begin{tabular}{lllcc}
\hline Material & Classification & \multicolumn{1}{c}{ Composition } & Batch & Manufacturer \\
\hline Filtek Z350 XT & Composite resin & $\begin{array}{l}\text { Bis-GMA, Bis-EMA, UDMA, TEGDMA, silica and zirconia } \\
\text { nanofillers, and agglomerated zirconia-silica nanoclusters. }\end{array}$ & HB004209993 & 3M ESPE \\
\hline Sealer 26 & $\begin{array}{l}\text { Endodontic } \\
\text { cement }\end{array}$ & $\begin{array}{l}\text { Powder: bismuth trioxide, calcium hydroxide, } \\
\text { hexamethylenetetramine, titanium dioxide. } \\
\text { Liquid: bisphenol epoxy }\end{array}$ & 260561 & Dentsply Sirona \\
\hline RelyX Ceramic Primer & Silane & 3-MPS, ethyl alcohol, water. & H0001504424 & 3 ESPE \\
\hline RelyX U200 & Resin cement & $\begin{array}{l}\text { Base: glass fiber, methacrylate phosphoric acid esters, } \\
\text { triethylene glycol dimethacrylate, silane-treated silica, } \\
\text { sodium persulfate. } \\
\text { Catalyst: glass fiber, substitute dimethacrylate, silane-treated } \\
\text { silica, sodium p-toluenesulfonate, calcium. }\end{array}$ & 3 ESPE \\
\hline
\end{tabular}

3-MPS, 3-methacryloxypropyl-trimethoxy silane; Bis-EMA, ethoxylated bisphenol-A glycol dimethacrylate; Bis-GMA, bisphenol-A diglycidyl ether dimethacrylate; TEGDMA, triethylene glycol dimethacrylate; UDMA, urethane dimethacrylate.

$\mathrm{MH}$ was established as the maximum load ( $\mathrm{P}$ max) divided by the contact surface area (A):

$\mathrm{MH}=\frac{\mathrm{P} \max }{\mathrm{A}}$.

The Eit was measured according to the following equation:

$\frac{1}{\mathrm{Er}}=\frac{\left(1-\mathrm{v}^{2}\right)}{\text { Eit }^{*}}+\frac{\left(1-\mathrm{vi}^{2}\right)}{\mathrm{Ei}}$,

where the Poisson coefficient of the specimen and the indenter are represented by $\mathrm{v}$ and vi, respectively, and the elastic indentation modulus of the indenter by Ei. The following equation was used to calculate the reduced modulus (Er):

$\mathrm{Er}=\frac{\sqrt{\pi}}{2 \sqrt{\mathrm{A}}} \mathrm{S}$,

where the designed area for contact printing is represented by A, and the stiffness of the material obtained from the slope of the unloading curve is represented by S; $\pi$ is 3.14 .

Eight specimens per group were used for push-out bond strength analysis. After PDT, the root canals were obturated by lateral condensation of gutta percha cones (Dentsply Sirona) and calcium hydroxide cement (Sealer 26; Dentsply Sirona). Coronal access was sealed with interim cement (White Cimpat; Septodont). The obturated teeth were stored at $100 \%$ relative humidity and $37^{\circ} \mathrm{C}$ for 7 days.

The glass-fiber post system used was WhitePost DCE\#2 (FGM). For luting the glass-fiber posts, the post spaces in all the specimens were prepared with a \#1 low-speed drill (Dentsply Sirona). A depth of $\pm 9 \mathrm{~mm}$ with reference to the working length of the teeth was standardized to remove the gutta percha cones. For root canal standardization, the drill corresponding to glass-fiber post \#2 was used. After removal of the gutta percha, the glass-fiber posts were placed in the post space to assess the adaptation of the posts. Before the adhesion process, the surfaces of the glassfiber posts were etched with $35 \%$ phosphoric acid (3M
ESPE) for 60 seconds. The acid was removed from the glassfiber posts by washing, and the posts were dried. A silane primer (RelyX Ceramic Primer; 3MESPE) was applied to the surfaces of the posts for 60 seconds. Thereafter, a jet of air was gently applied to dry the glass-fiber posts, and the posts were not further manipulated to prevent contamination. ${ }^{24}$

The canals were irrigated with physiological saline $(0.9 \%)$ to remove any residual gutta percha. Then, a jet of air and sterile paper points were used to dry the post spaces before luting with a resin cement (RelyX U200; 3M ESPE) and polymerizing for 40 seconds from the occlusal surface using a light-polymerization unit (Ultraled; Dabi Atlante) with a light intensity of $1125 \mathrm{~mW} / \mathrm{cm}^{2} .{ }^{26}$ After luting the fiber posts, the coronal access was sealed with composite resin (Filtek Z350 XT; 3M ESPE), and the specimens were stored at $37^{\circ} \mathrm{C}$ and $100 \%$ relative humidity for 7 days. To obtain slices of approximately $1.3-\mathrm{mm}$ thickness, the experimental specimens were cut perpendicular to the long axis of the root with a low-speed diamond saw (Isomet 5000; Buehler) under water cooling. ${ }^{13,24}$ The slice thickness, which was used in the bond strength value calculations, was measured using digital calipers (Mitutoyo).

For the push-out test, a universal testing machine was used (DL 3000; EMIC). The active tip coincided with the center of the fiber post, applying a compressive load in a vertical direction with a speed of $0.5 \mathrm{~mm} / \mathrm{min} .22,27-29$ The bond strength values were calculated using an arithmetic mean between the different thirds of each dental specimen. The bond strength values were calculated according to the following equation ${ }^{30}$ :

$\mathrm{Ru}=\mathrm{F} / \mathrm{A}$,

where the bond strength is $\mathrm{Ru}$, maximum force is $\mathrm{F}$, and the area of the bonding interface is A. A was obtained according to the following equation ${ }^{30}$ :

$A=\pi\left(R_{1}+R_{2}\right) \sqrt{\left(R_{1}-R_{2}\right)}{ }^{2}+h^{2}$,

where $\pi$ is 3.14, $R_{1}$ and $R_{2}$ are the coronal and apical arc radii of the post segment, respectively, and $h$ is the height of the post measured using digital calipers. 
Table 2. Mean \pm standard deviation (GPa) values of Martens hardness $(\mathrm{MH})$ and elastic indentation modulus (Eit) of intraradicular dentin as a function of photosensitizer agents used in photodynamic therapy

\begin{tabular}{lcc}
\hline Group & MH & Eit \\
\hline Control & $0.19 \pm 0.17^{\mathrm{A}}$ & $3.46 \pm 3.70^{\mathrm{A}}$ \\
\hline $\mathrm{MB}_{50}$ & $0.11 \pm 0.03^{\mathrm{AB}}$ & $2.89 \pm 2.23^{\mathrm{A}}$ \\
\hline $\mathrm{MB}_{100}$ & $0.10 \pm 0.02^{\mathrm{AB}}$ & $2.28 \pm 0.48^{\mathrm{A}}$ \\
\hline $\mathrm{C}_{500}$ & $0.08 \pm 0.01^{\mathrm{B}}$ & $1.67 \pm 0.29^{\mathrm{AB}}$ \\
\hline $\mathrm{C}_{1000}$ & $0.05 \pm 0.01^{\mathrm{C}}$ & $1.27 \pm 0.25^{\mathrm{B}}$ \\
\hline
\end{tabular}

$\mathrm{C}_{500}$, curcumin $500 \mathrm{mg} / \mathrm{L} ; \mathrm{C}_{1000}$, curcumin $1000 \mathrm{mg} / \mathrm{L} ; \mathrm{MB}_{50}$, methylene blue $50 \mathrm{mg} / \mathrm{L}$; $\mathrm{MB}_{100}$, methylene blue $100 \mathrm{mg} / \mathrm{L}$. Different superscript letters indicate statistically significant differences for each mechanical property analyzed $(P<.05)$.

A stereomicroscope was used at magnifications $\times 6$ and $\times 66$ to analyze the failure mode of the specimens. Failure modes were classified into 3 groups: (1) adhesive failure, (2) cohesive failure in dentin, and (3) mixed failure. Representative specimens were subjected to sputter coating with gold (BAL-TEC SCD 050; Balzers) and analyzed using scanning electron microscopy (SEMJSM5600LV; JEOL) to demonstrate the patterns of fracture. $^{31,32}$ Data were submitted to a normality test (Shapiro-Wilk test). Mechanical properties data were submitted to the nonparametric Kruskal-Wallis test for comparison between the groups $(\alpha=.05)$. Bond strength data were submitted to 1-way ANOVA and the Fisher least significant difference test $(\alpha=.05)$.

\section{RESULTS}

The Kruskal-Wallis test of the mechanical properties indicated higher hardness values $(\mathrm{MH})$ for the control group than the curcumin groups at both concentrations $\left(\mathrm{C}_{500}\right.$ and $\left.\mathrm{C}_{1000}\right)(P<.05)$. No statistically significant difference was found among the control group and the methylene blue groups at either concentration $\left(\mathrm{MB}_{50}\right.$ and $\left.\mathrm{MB}_{100}\right)$ (P>.05). The effect of the application of the different PSs in the PDT was also supported by the Eit values, in which the $C_{1000}$ group showed fewer Eit values than the $\mathrm{MB}_{50}, \mathrm{MB}_{100}$, and control groups ( $\left.P=.001\right)$ (Table 2).

The results of ANOVA for push-out bond strength values indicated statistically significant differences among the PSs used $(P<.001)$. Table 3 shows that the push-out bond strength values for the $C_{500}$ and $C_{1000}$ groups were statistically significantly higher than those of the control and $\mathrm{MB}_{100}$ groups $(P<.05)$. A predominance of mixed-type failure was found in the $C_{1000}$ and control groups, whereas in the $\mathrm{C}_{500}$ and $\mathrm{MB}_{100}$ groups, cohesivetype failure predominated (Fig. 1). Representative SEM images are presented in Figure 2.

\section{DISCUSSION}

The use of different PSs for PDT influenced the mechanical properties of intraradicular dentin, as well as the bond strength of glass-fiber posts to dentin (Tables 2, 3);
Table 3. Mean \pm standard deviation (MPa) values of extrusion bond strength (push-out strength test) of intraradicular dentin as function of photosensitizer agents used in photodynamic therapy

\begin{tabular}{lcccc}
\hline Control Group & $\mathbf{M B}_{\mathbf{5 0}}$ Group & $\mathbf{M B}_{\mathbf{1 0 0}}$ Group & $\mathbf{C}_{\mathbf{5 0 0}}$ Group & $\mathbf{C}_{\mathbf{1 0 0 0}}$ Group \\
\hline $1.64 \pm 0.96^{\mathrm{B}}$ & $1.71 \pm 0.85^{\mathrm{AB}}$ & $0.67 \pm 0.51^{\mathrm{B}}$ & $3.28 \pm 1.29^{\mathrm{A}}$ & $3.20 \pm 1.14^{\mathrm{A}}$ \\
\hline
\end{tabular}

$\mathrm{C}_{500}$, curcumin $500 \mathrm{mg} / \mathrm{L} ; \mathrm{C}_{1000}$, curcumin $1000 \mathrm{mg} / \mathrm{L} ; \mathrm{MB}_{50}$, methylene blue $50 \mathrm{mg} / \mathrm{L}$; $\mathrm{MB}_{100}$, methylene blue $100 \mathrm{mg} / \mathrm{L}$. Different letters indicate statistically significant differences $(P<.05)$

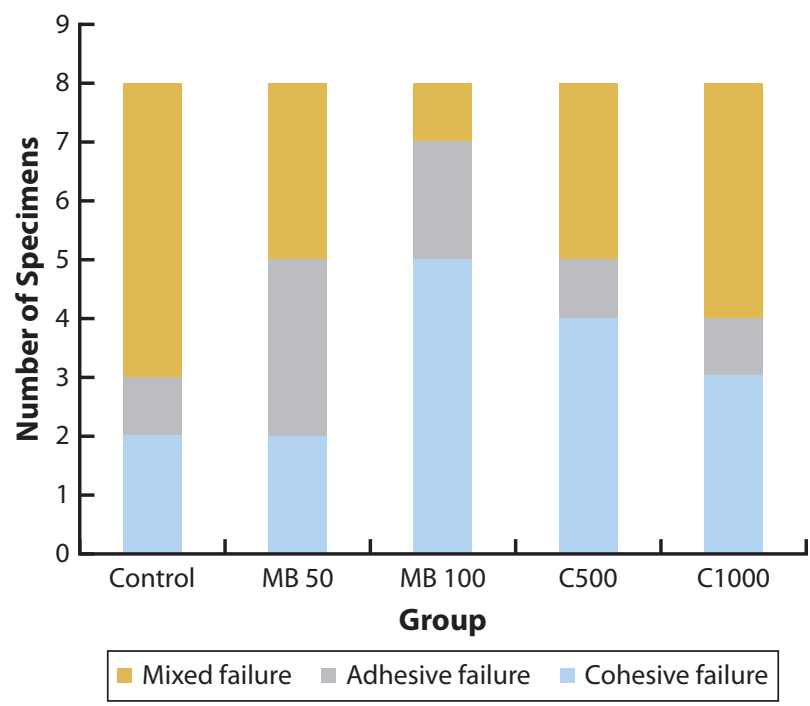

Figure 1. Incidence of fracture patterns (specimen numbers) according to type of failure. $C_{500}$, curcumin $500 \mathrm{mg} / \mathrm{L} ; C_{1000}$, curcumin $1000 \mathrm{mg} / \mathrm{L}$; $\mathrm{MB}_{50}$, methylene blue $50 \mathrm{mg} / \mathrm{L} ; \mathrm{MB}_{100}$, methylene blue $100 \mathrm{mg} / \mathrm{L}$.

thus, the null hypothesis of the study was rejected. Although these PSs are commonly used at these concentrations in clinical practice, the authors are unaware of previous studies that have analyzed the effects of these PSs on intraradicular dentin after PDT. The PS used must not alter the mechanical properties of the dentin substrate during PDT because such alterations can influence the behavior of the dentin-restoration interface and reduce the fracture resistance of the root. 3,7

The curcumin PS promoted significant surface changes in the dentin substrate; therefore, its photoactivation did not lead to formation of singlet oxygen (Table 2). However, the photoactivation of curcumin promotes hydrogen peroxide formation. ${ }^{33,34}$ Some studies have reported that hydrogen peroxide formation is less cytotoxic than the formation of singlet oxygen, but its period of action is relatively longer, ${ }^{33,34}$ supporting the results of this study.

The lowest $\mathrm{MH}$ and Eit values for intraradicular dentin were noticed for the groups in which curcumin was used as PS, at either concentration and at the higher concentration (Table 2). The products synthesized in the photodynamic action of this PS are anions of superoxide and hydrogen peroxide, as previously reported. ${ }^{33,34}$ These anionic components are able to bind to cationic 

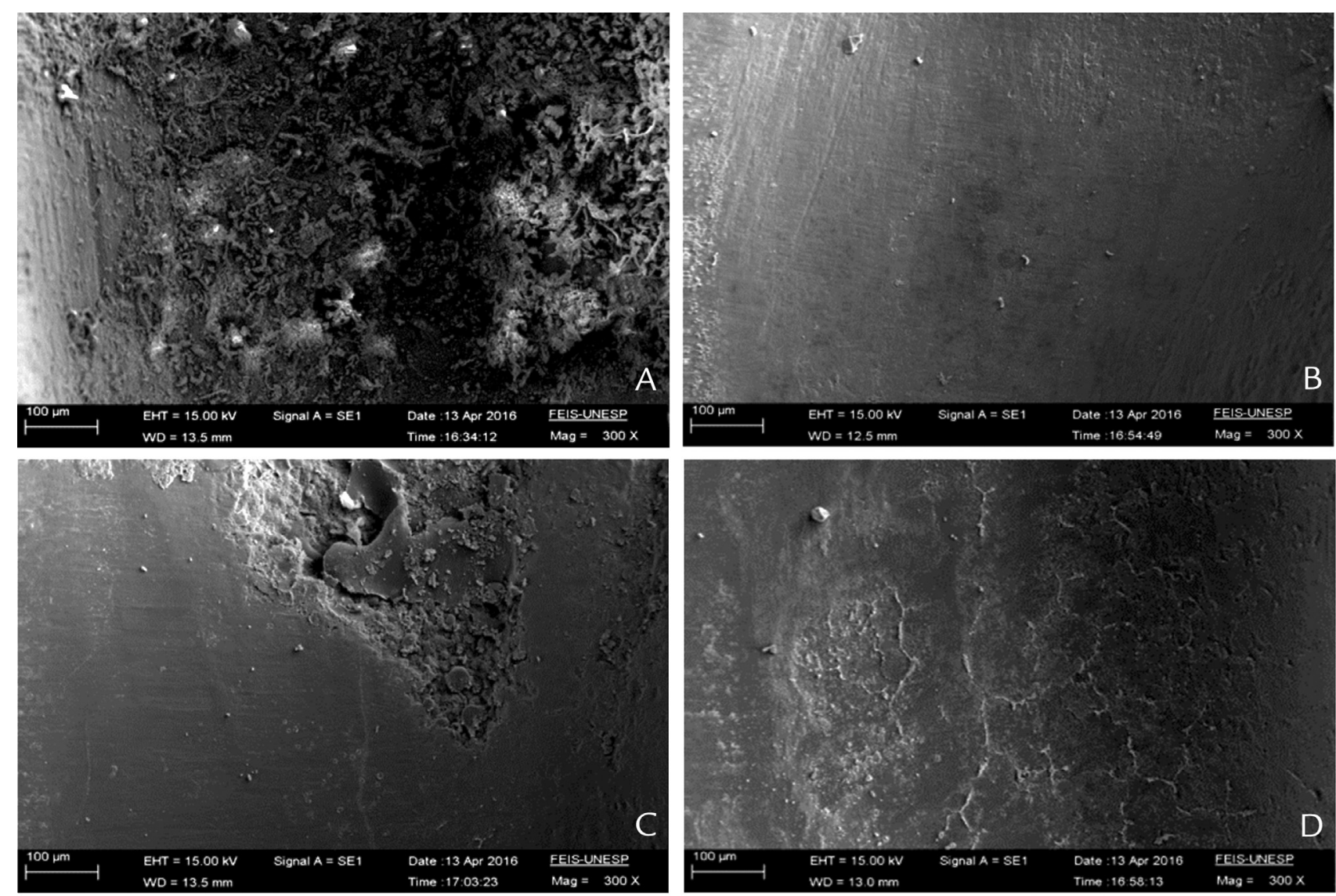

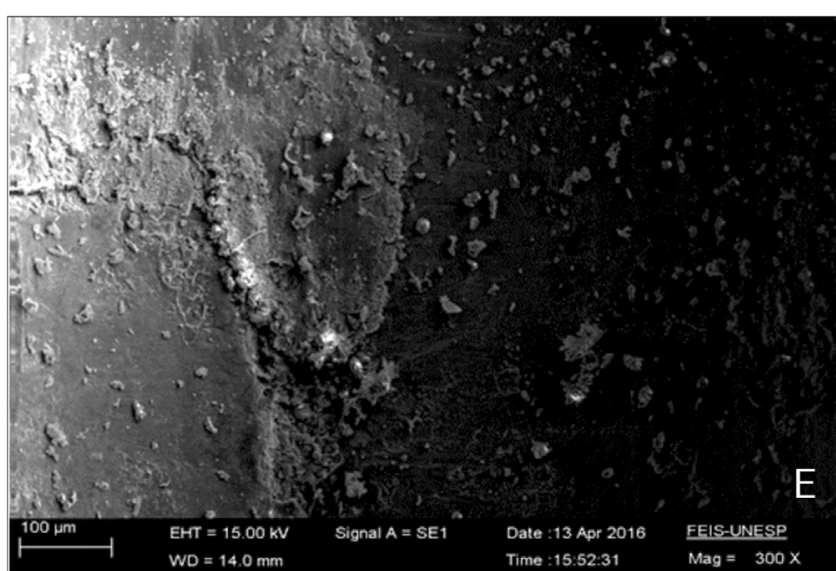

molecules, such as the calcium present in the hydroxyapatite crystals. ${ }^{12}$ Considering that calcium is present in the calcium carbonate complex of intraradicular dentin, curcumin could induce alterations in the relation, of $\mathrm{Ca}_{10}\left(\mathrm{PO}_{4}\right)_{6}(\mathrm{OH})_{2}$, explaining the lower Eit values of dentin submitted to PDT with this PS.

Methylene blue is a cationic substance that binds to anionic molecules, such as the phosphate present in hydroxyapatite, thereby influencing the calcium/phosphate ratio. The reaction between this PS and phosphate would result in precipitates acting as a physical barrier
Figure 2. Scanning electron micrographs of representative specimens (original magnification $\times 300$ ). A, Mixed failure of dentin irrigated with deionized water solution (control group). $B$, Adhesive failure of dentin after treatment with methylene blue $50 \mathrm{mg} / \mathrm{L}\left(\mathrm{MB}_{50}\right.$ group). $\mathrm{C}$, Cohesive failure of dentin after treatment with methylene blue $100 \mathrm{mg} / \mathrm{L}\left(\mathrm{MB}_{100}\right.$ group). $D$, Cohesive failure of dentin after treatment with curcumin 500 $\mathrm{mg} / \mathrm{L}\left(\mathrm{C}_{500}\right.$ group). $\mathrm{E}$, Mixed failure of dentin after treatment with curcumin $1000 \mathrm{mg} / \mathrm{L}\left(\mathrm{C}_{1000}\right.$ group).

and reducing the interaction between the resin cement and the surface of the dentin. ${ }^{32}$ This phosphate-PS relationship could explain the lower bond strength values of the $M_{100}$ group than those of the $C_{500}$ and $\mathrm{C}_{1000}$ groups. When the scanning electron microscopy images of the $\mathrm{MB}_{50}$ and $\mathrm{MB}_{100}$ groups were compared (Fig. 2B, 2C), a different fracture pattern could be seen, showing that the group exposed to the lowest concentration had a higher incidence of adhesive failures, whereas the group exposed to the highest concentration had predominantly cohesive-type failures (Fig. 1). 
Methylene blue is a hydrophilic compound that allows water sorption to deteriorate the bond strength. ${ }^{33}$ According to a study by Wainright et al, ${ }^{13}$ the intensity of water sorption is directly related to the concentration of the PS used, corroborating the results found in this study (Table 3). However, curcumin is a hydrophobic polyphenol, which is poorly soluble in water, ${ }^{35}$ explaining the highest values of bond strength for this PS (Table 3). In addition, the resin cement used in this study has a hydrophobic character, ${ }^{26}$ enhancing the integrity of the bond strength of the glass-fiber posts to the intraradicular dentin. The integrity of the adhesive interface can be seen in the image of the $\mathrm{C}_{1000}$ group (Fig. 2E), which showed a higher incidence of mixed failures (Fig. 1).

The higher values of bond strength obtained with curcumin as PS can also be explained by the anionicity of the component, which promotes changes in the calcium complex of the dentin substrate. ${ }^{33,34}$ Thus, the flow of the resin cement may have interacted with the changed surface of the intraradicular dentin, promoting micromechanical retention and consequently resulting in higher bond strength values in the push-out test.

However, different PSs, at various concentrations, will not always obtain satisfactory results in both the analyses. The use of methylene blue at $50 \mathrm{mg} / \mathrm{L}$ is an appropriate choice as a PS, as it promoted satisfactory mechanical properties of the dentin substrate and bond strength of the adhesive interface.

The study limitations include the use of bovine teeth, difficulty of standardizing the preparation in areas with difficult access, and nonhomogeneity of the substrate. Additional studies should investigate PDT further and should seek to identify different types and concentrations of PSs, different types of lasers and LED for use in PDT, and the time and technique used for the application of the PSs.

\section{CONCLUSIONS}

Based on the findings of this in vitro study, the following conclusions were drawn:

1. $\mathrm{MH}$, Eit, and bond strength of intraradicular dentin were influenced by the PS used for PDT.

2. Methylene blue at a concentration of $50 \mathrm{mg} / \mathrm{L}$ is a suitable alternative for endodontic treatment involving PDT, as it does not alter the mechanical properties or bond strength of the intraradicular dentin and could therefore be implemented in PDT before luting the glass-fiber posts.

\section{REFERENCES}

1. Estrela C, Holland R, Estrela CR, Alencar AH, Sousa-Neto MD, Pécora JD. Characterization of successful root canal treatment. Braz Dent J 2014;25:3-11.
2. Faria-e-Silva AL, Menezes Mde S, Silva FP, Reis FR, Moraes RR. Intraradicular dentin treatments and retention of fiber posts with self-adhesive resin cements. Braz Oral Res 2013;27:14-9.

3. Marcelino AP, Bruniera JF, Rached-Junior FA, Silva SR, Messias DC. Impact of chemical agents for surface treatment on microhardness and flexural strength of root dentin. Braz Oral Res 2014;28:1-6.

4. Wu MK, Dummer PM, Wesselink PR. Consequences of and strategies to deal with residual post-treatment root canal infection. Int Endod J 2006;39:343-56.

5. Guo I, Yang D, Okamura H, Teramachi J, Ochiai K, Qiu L, et al. Calcium hydroxide suppresses Porphyromonas endodontalis lipopolysaccharideinduced bone destruction. J Dent Res 2014;93:508-13.

6. Gonçalvez LS, Rodrigues RC, Andrade Junior CV, Soares RG, Vettore MV The effect of sodium hypochlorite and chlorhexidine as irrigant solutions for root canal disinfection: a systematic review of clinical trials. J Endod 2016;42: 527-32.

7. Viapiana R, Sousa-Neto MD, Souza-Gabriel AE, Alfredo E, Silva-Sousa YT. Microhardness of radicular dentin treated with $980-\mathrm{nm}$ diode laser and different irrigant solutions. Photomed Laser Surg 2012;30:102-6.

8. Silva LAB, Nelson-Filho P, Leonardo MR, Rossi MA, Pansani CA. Effect of calcium hydroxide on bacterial endotoxin in vivo. J Endod 2002;28:94-8.

9. Vera J, Siqueira JF Jr, Ricucci D, Loghin S, Fernández N, Flores B, et al. One versus two-visit endodontic treatment of teeth with apical periodontitis: a histobacteriologic study. J Endod 2012;38:1040-52.

10. Siqueira JF Jr, Rôças IN, Ricucci D, Hülsmann M. Causes and management of pos-treatment apical periodontitis. Braz Dent J 2014;16:305-12.

11. Berbert FL, Sivieri-Araujo G, Ramalho LT, Pereira SA, Rodrigues DB, de Araújo MS. Quantification of fibrosis and mast cells in the tissue response of endodontic sealer irradiated by low-level laser therapy. Lasers Med Sci 2011;26:741-7.

12. Pascon FM, Kantovitz KR, Soares LE, Santo AM, Martin AA, PuppinRontani RM. Morphological and chemical changes in dentin after using endodontic agents: fourier transform Raman spectroscopy, energy-dispersive $\mathrm{x}$-ray fluorescence spectrometry, and scanning electron microscopy study J Biomed Opt 2012;17:075008.

13. Wainwright M, Phoenix DA, Rice L, Burrow SM, Waring I. Increased cytotoxicity and phototoxicity in the methylene blue series via chromophore methylation. J Photochem Photobiol B 1997;40:233-9.

14. Allison RR, Moghissi K. Photodynamic Therapy (PDT): PDT Mechanisms. Clin Endosc 2013;46:24-9.

15. Rego-Filho FG, de Araujo MT, de Oliveira KT, Bagnato VS. Validation of photodynamic action via photobleaching of a new curcumin-based composite with enhanced water solubility. J Fluoresc 2014;24:1407-13.

16. Rego Filho Fde A, Caldas RA, Kurachi C, Bagnato VS, de Araujo MT. Possibility for the conjugated use of photodynamic therapy and electrosurgical devices. PLoS One 2015;18:e0136194.

17. Juric IB, Plecko V, Panduric DG, Anic I. The antimicrobial effectiveness of photodynamic therapy used as an addition to the conventional endodontic re-treatment: a clinical study. Photodiagnosis Photodyn Ther 2014;11:549-55.

18. Sivieri-Araujo G, Queiroz ÍOA, Fabbro RD, Esteves F, Cintra LTA Duarte PCT, et al. Rat tissue reaction and cytokine production induced by antimicrobial photodynamic therapy. Photodiagnosis Photodyn Ther 2017:18:315-8.

19. Gomes-Filho JE, Sivieri-Araujo G, Sipert CR, da Silva Santos LM, de Azevedo Queiroz ÍO, Men Martins C, et al. Evaluation of photodynamic therapy on fibroblast viability and cytokine production. Photodiagnosis Photodyn Ther 2016;13:97-100.

20. Sivieri-Araujo G, Santos LMS, Queiroz IOA, Wayama MT, Yamanari GH, Martins CM, et al. Photodynamic therapy in Endodontics: use of a supporting strategy to deal with endodontic infection. Dental Press Endod 2013;3:52-8

21. Shahdad SA, McCabe JF, Bull S, Rusby S, Wassell RW. Hardness measured with traditional Vickers and Martens hardness method. Dent Mater 2007:23: 1079-85.

22. Mumcu E, Erdemir U, Topcu FT. Comparison of micro push-out bond strengths of two fiber posts luted using simplified adhesive approaches. Dent Mater 2010;29:286-96.

23. Berger SB, Pavan S, Vidal Cde M, Santos PH, Giannini M, Bedran-Russo AK. Changes in the stiffness of demineralized dentin following application of tooth whitening agents. Acta Odontol Scand 2012;70:56-60.

24. Suzuki TY, Gomes-Filho JE, Gallego J, Pavan S, Dos Santos PH Fraga Briso AL. Mechanical properties of components of the bonding interface in different regions of radicular dentin surface. J Prosthet Dent 2015;113:54-61.

25. Guedes AP, Moda MD, Suzuki TY, Godas AG, Sundfeld RH, Briso AL, et al. Effect of fluoride-releasing adhesive systems on the mechanical properties of eroded dentin. Braz Dent J 2016;27:153-9.

26. Kim YK, Son JS, Kim KH, Kwon TY. Influence of surface energy parameters of dental self-adhesives resin cements on bond strength to dentin. J Adhes Sci Technol 2013;27:1778-89.

27. Topcu FT, Erdemir U, Sahinkesen G, Mumcu E, Yildiz E, Uslan I. Push-out bond strengths of two post types bonded with different dentin bonding agents. J Biomed Mater Res B Appi Biomater 2010;93:359-66. 
28. Onay EO, Korkmaz Y, Kiremitci A. Effect of adhesives system type and root region on the push-out strength of glass-fibre posts to radicular dentin. Int Endod J 2010;43:259-68.

29. Wu WC, Wang DM, Lin YC, Dai CA, Cheng KC, Hu MS, et al. Hydrogen bonds of a novel resin cement contribute to high adhesion strength to human dentin. Dent Mater 2016;32:114-24.

30. Bitter K, Polster L, Askar H, von Stein-Lausnitz M, Sterzenbach G. Effect of final irrigation protocol and etching mode on bond strength of a multimode adhesive in the root canal. J Adhes Dent 2017:8:245-52.

31. Suzuki TYU, Godas AGL, Guedes APA, Catelan A, Pavan S, Briso ALF, et al Microtensile bond strength of resin cements to caries-affected dentin. J Prosthet Dent 2013;110:47-55.

32. Di Hipólito V, Rodrigues FP, Piveta FB, Azevedo Lda C, Bruschi Alonso RC Silikas N, et al. Effectiveness of self-adhesive luting cements in bonding to chlorhexidine- treated dentin. Dent Mater 2012;28:495-501.

33. Dahl TA, McGowan WM, Shand MA, Srinivasan VS. Photokilling of bacteria by the natural dye curcumin. Arch Microbiol 1989;151:183-5.

34. Chignell CF, Bilski P, Reszka KJ, Motten AG, Sik RH, Dahl TA. Spectral and photochemical properties of curcumin. Photochem Photobiol 1994:59: 295-302.
35. Prasad S, Gupta S, Tyagi AK, Aggarwal BB. Curcumin, a component of golden spice: from bedside to bench and back. Biotechnol Adv 2014;32: 1053-64.

Corresponding author:

Professor Gustavo Sivieri-Araujo

Department of Restorative Dentistry

School of Dentistry

São Paulo State University (UNESP)

Rua José Bonifácio, 1193, Araçatuba 16015-050

BRAZIL

Email: gustavosivieri@foa.unesp.br

Acknowledgments

The authors thank Dr Juno Gallego of the Department of Mechanical Engineering,

School of Natural Sciences and Engineering, São Paulo State University (UNESP),

Ilha Solteira, for contributing to the analyses of mechanical properties.

Copyright ( 2018 by the Editorial Council for The Journal of Prosthetic Dentistry. 